Florida State University College of Law

Scholarship Repository

Scholarly Publications

$5-2014$

\title{
The Truth-Justice Tradeoff: Perceptions of Decisional Accuracy and Procedural Justice in Adversarial and Inquisitorial Legal Systems
}

Justin Sevier

Florida State University College of Law

Follow this and additional works at: https://ir.law.fsu.edu/articles

Part of the Law Commons, Psychology Commons, and the Public Policy Commons

\section{Recommended Citation}

Justin Sevier, The Truth-Justice Tradeoff: Perceptions of Decisional Accuracy and Procedural Justice in Adversarial and Inquisitorial Legal Systems, 20 PSYCH. PUB. PoL'Y \& L. 212 (2014),

Available at: https://ir.law.fsu.edu/articles/121

This Article is brought to you for free and open access by Scholarship Repository. It has been accepted for inclusion in Scholarly Publications by an authorized administrator of Scholarship Repository. For more information, please contact efarrell@law.fsu.edu. 
THE TRUTH-JUSTICE TRADEOFF

The Truth-Justice Tradeoff: Perceptions of Decisional Accuracy and Procedural Justice in Adversarial and Inquisitorial Legal Systems

Justin Sevier 


\begin{abstract}
Two studies provide empirical support for Thibaut and Walker's (1978) theory that inquisitorial and adversarial dispute resolution systems are associated with different psychological values: the pursuit of truth and the pursuit of justice. Study 1 suggests that, in civil and criminal disputes, the adversarial system is perceived to produce less truth than it does justice, and less truth than does the inquisitorial system. Conversely, the inquisitorial system is perceived to produce less justice than it does truth, and less justice than does the adversarial system. Study 2 examines how legal outcomes moderate litigants' perceptions of the truth and justice produced by these dispute resolution systems. Study 2 suggests that perceptions of the truth and justice provided by the adversarial system are highly sensitive to the outcome of the dispute, whereas perceptions of the truth and justice provided by the inquisitorial system are not affected by dispute outcomes. Implications for Thibaut and Walker's theory are discussed. Keywords: dispute resolution, comparative dispute systems, procedural justice, decisional accuracy, courts
\end{abstract}


Psychologists, economists, political scientists, and legal scholars have investigated the merits of different legal procedures for resolving social disputes (Anderson \& Otto, 2003; Block \& Parker, 2004; Dewatripont \& Tirole, 1999; Finegan, 2009; Kessler, 2005; MacCoun, 1998; Moohr, 2004; Mosteller, 2011; Parisi, 2002; Roach, 2010; Van Koppen \& Penrod, 2003; Wolfe \& Proszek, 1997). Most of the research into these legal systems attempts to determine which system is "better" for resolving social disputes.

The systems that have received the most scholarly attention are the autocratic, inquisitorial model and the disputing, adversarial model of decision making (see, e.g., Van Koppen \& Penrod, 2003). The adversarial system is characterized by an impartial decision maker who evaluates contrasting presentations by adversaries to a dispute, evaluates the merits of those presentations, and renders a decision that distributes a positive outcome to one party and a corresponding negative outcome to the other (Thibaut \& Walker, 1978; Van Koppen \& Penrod, 2003). In contrast, the inquisitorial system is characterized by a decision maker who retains substantial power to elicit evidence in an inquiry aimed at discovering the true facts underlying a dispute (Crombag, 2003; Damaska, 1973; Hayden \& Anderson, 1979).

Thibaut and Walker (1978) assessed the merits of the inquisitorial and adversarial systems in terms of the primary psychological objectives associated with each procedure. They argued that the inquisitorial procedure is optimal for resolving disputes that are high in "cognitive conflict" - in which arriving at the correct factual answer is of primary importance-because the procedure is well suited for discovering the true facts underlying the dispute (p. 543). In support, Thibaut and Walker noted that the procedure 
allows a disinterested third party a single selection strategy for gathering appropriate evidence without potential bias from parties who might have a stake in the dispute (see Damaska, 1973). In contrast, Thibaut and Walker argued that the adversarial procedure is optimal for disputes high in "conflict of interest"- - in which the primary objective is to allocate resources fairly among litigants - because the adversarial procedure is well suited for producing justice (p. 544). Thibaut and Walker noted that the adversarial procedure allows parties to present more information directly to the decision maker, which provides to the decision maker individualized information with respect to how to allocate resources between the parties (see also MacCoun, 1998).

Little research has evaluated whether Americans' perceptions of the adversarial and inquisitorial systems align with Thibaut and Walker's (1978) framework. Two studies reported here examine this question. The first study examines whether, in the context of a dispute involving scientific evidence, these systems are perceived as prioritizing truth or justice. The second study examines whether outcome favorability moderates participants' perceptions of the truth and justice provided by these procedures. Theoretical implications are discussed.

\section{Decisional Accuracy and the Pursuit of Truth}

Researchers have studied a decision-making procedure's pursuit of truth, or decisional accuracy, by examining the objective truth that it produces and the perceptions of truth that it produces among litigants. Although this study focuses on perceptions of truth, the literature from both fields is informative. Thibaut and Walker (1978) hypothesized that the inquisitorial system produces objective truth by vesting control over the flow of evidence with the decision maker. This suggests that the inquisitorial 
system produces greater truth than does the adversarial system, in which biased advocates control the presentation of potentially biased evidence to the decision maker (Thibaut \& Walker, 1978). A competing hypothesis states, however, that evidence may be vetted more vigorously in the adversarial system, where motivated advocates cross-examine their adversary's witnesses and expose weaknesses in their adversary's case (Thibaut \& Walker, 1975; see also Rosenberg, Weinstein, Smit \& Korn, 1976).

Lind, Thibaut, \& Walker (1973) tested these competing hypotheses. Lind et al. asked participants to gather facts — and to transmit those facts to the court — as either a client-centered, adversarial advocate or as an unbiased, inquisitorial investigator. The study revealed few differences in fact-finding diligence between participants in the inquisitorial and adversarial conditions, but the study revealed substantial differences in the transmission of facts. Participants in the adversarial condition transmitted to the court nearly none of the facts they uncovered that disfavored their client, while participants in the inquisitorial condition transmitted to the decision maker nearly the same proportion of positive and negative facts that they uncovered. The study suggests that the adversarial system may shield from the decision maker facts that are unfavorable to the parties, which in turn may lead to inaccurate decisions. Other researchers have replicated these findings (Sheppard \& Vidmar, 1980; see also Lind \& Walker, 1979).

A smaller body of research, however, suggests that the adversarial system may counteract decision-maker bias in a manner that the inquisitorial system does not. Thibaut et al. (1972) hypothesized that inquisitorial decision makers may prematurely characterize a defendant as guilty if the initial facts of the defendant's case are similar to the facts of other cases in which defendants were found guilty. This, in turn, may lead to 
the biased assimilation of facts in the current defendant's case. Thibaut et al. tested this hypothesis by varying (a) the information about prior cases that was given to the decision maker and (b) the type of procedure used to evaluate the dispute. The researchers found that judgments of decision makers in the inquisitorial condition were influenced by the outcomes of similar prior cases, whereas the judgments of decision makers in the adversarial condition were not. Thibaut et al. concluded that at least one aspect of the adversarial system reduces bias better than does the inquisitorial system. Other researchers have found that judges are prone to the same types of decision making biases that afflict jurors, which supports Thibaut et al.'s conclusion (see Guthrie, Rachlinski, \& Wistrich, 2001; Landsman \& Rakos, 1994).

The results of studies examining perceptions of the truth produced by these systems are similarly complex. Austin and Tobiasen (1984) examined perceptions of the truth produced under the adversarial and inquisitorial systems and found that, depending on the circumstances, people sometimes perceive the inquisitorial system as producing more accurate judgments and sometimes perceive the adversarial system as more accurate. Participants watched a videotaped trial, read a transcript, or read a summary of legal proceedings, and then ranked the different procedures with respect to several dependent measures, including accuracy. Across all three media, slightly over half of the participants characterized a non-adversarial paradigm as the most accurate, but slightly under half chose the adversarial paradigm. Moreover, no pattern emerged for the individual media; a majority of participants sometimes chose non-adversarial procedures as the most accurate (for example, when they watched a video of a trial simulation or 
read a trial transcript), whereas a majority sometimes chose the adversarial procedure instead (for example, when participants read a summary of a trial).

In sum, a lack of clarity exists in the current literature with respect to the objective and perceived accuracy of decisions produced by adversarial and inquisitorial legal systems. Although research findings are inconclusive, the weight of the research supports the hypothesis that the inquisitorial system is perceived to produce more truth than does the adversarial system.

\section{Procedural Justice and the Pursuit of Fairness}

Social psychologists have defined the justice afforded by decision-making procedures as the perception among people that the decision-making process itself is fair and equitable (Thibaut \& Walker, 1975; see also Lind \& Tyler, 1988; Wendorf et al., 1999). Researchers have found that the decision maker's neutrality, the degree of respect that the decision maker confers on the parties, the amount of voice and control that the parties have over the legal dispute, and the degree to which parties can trust the decision maker's motive to be fair influence people's perceptions of procedural justice (Tyler, 2006; Tyler, 2000; Tyler, 1987; Tyler \& Lind, 1992).

If perceptions of procedural justice are determined, in part, by the amount of voice and control that the decision maker affords litigants, the adversarial model — which affords litigants more control over the proceedings than does a pure inquisitorial modelshould be perceived as more just. To the extent that heightened perceptions of procedural justice lead to greater preferences for a procedure, a body of research supports this hypothesis. Thibaut \& Walker (1975) found that, controlling for the outcome of a legal dispute, people generally report higher preferences for adversarial procedures compared 
to inquisitorial procedures. Other researchers have found similar effects (see, e.g., Houlden, LaTour, Walker, \& Thibaut, 1978; LaTour, Houlden, Walker, \& Thibaut, 1976; Walker, LaTour, Lind, \& Thibaut, 1974).

A smaller body of research, however, suggests that the adversarial system might not always be perceived as more just than the inquisitorial procedure. Anderson and Otto (2003) found cultural differences with respect to litigants' perceptions of procedural fairness. Although Americans preferred the adversarial system and perceived it to be fairer than the inquisitorial system, Dutch participants preferred the inquisitorial system and perceived it to be fairer than the adversarial system. Further, Austin and Tobiasen (1984) have found that inquisitorial procedures are perceived as just as fair as adversarial procedures if participants believe that the procedures are implemented reasonably (see also Brekke, Enko, Clavet \& Seelau, 1991).

In sum, the current literature examining litigants' perceptions of the justice provided by the inquisitorial and adversarial systems is mixed. Although a litigant's culture and the manner in which a legal procedure is implemented can affect litigants' perceptions of procedural justice, the weight of the research and theory suggests that the adversarial system produces greater perceptions of justice than does the inquisitorial system.

\section{Pilot Study}

We developed two scales for use in the studies reported here: a measure of participants' perceptions of the decisional accuracy of the legal system to which they are exposed, and a measure of their perceptions of the amount of procedural justice that it 
produces. We ran a pilot study to evaluate the convergent and discriminant validity of these scales.

\section{Methods}

One hundred American participants were recruited via the online participation service, Amazon Mechanical Turk, to participate in an online study in return for nominal payment. Research indicates that Amazon Mechanical Turk is a valid source of data for behavioral science researchers (Berinsky, Huber, \& Lenz, 2012; Buhrmester, Kwang, \& Gosling, 2011; Mason \& Suri, 2010). Participants read a vignette (see Appendix) that served as the experimental manipulation in Study 1 and answered a series of questions designed to measure their perceptions of how well the legal procedure would produce factually accurate decisions and the degree to which the procedure was just. Eleven items were developed for our scales: five items were designed to measure perceptions of decisional accuracy while six were designed to measure perceptions of justice.

The items measuring truth perceptions were: "How likely is it that a decision reached using this procedure will be accurate?" (“Accurate"); "How likely is it under this procedure that a court will uncover the true facts?" ("True"); "How likely is it that this procedure will reveal the right information that the court needs to make a decision?” ("Right Information"); "How much confidence would you have in the court to make a good factual decision?" ("Factual Decision"); and "How much faith do you have in a court using this procedure to resolve disputes correctly on the facts?" (“Correct”).

The items used to measure procedural justice perceptions were: "How much control does this procedure give people over the outcome?" (“Gives Control"); "How much does this procedure afford people an adequate opportunity to present arguments to 
the decision maker?" ("Presents Arguments"); "How much does this procedure give people an adequate opportunity to make their points?" (“Gives Voice”); "How much does this procedure adequately protect people's rights when they bring forth a legal dispute?" ("Protects Rights"); “To what extent does this procedure treat people with dignity and respect?" ("Provides Dignity"); and "To what extent does this procedure allow the court to take seriously people's legal disputes?" (“Takes Disputes Seriously”).

Additionally, participants answered the following item: "On the whole, how fair did you find the procedure that was used to resolve the legal dispute?" Participants responded to all questions on a seven-point Likert scale.

\section{Results and Discussion}

We analyzed these items using a principal component analysis with an oblique rotation. Two factors emerged with eigenvalues greater than 1.00, which together explained $78.74 \%$ of the total variance. As predicted, the items "Correct," "Accurate," "True," "Right Information," and "Factual Decision" loaded together onto one factor, each with a factor loading above .87. Also as predicted, the items "Protects rights," “Takes Disputes Seriously," “Gives Voice," "Presents Arguments," “Gives Control,” and "Provides Dignity," loaded together onto a second factor, each with a factor loading above .67. This suggests that the truth and justice items measured distinct latent constructs. The items that loaded onto the separate dimensions were averaged to form two scales, Truth (5 items, $\alpha=.96$ ) and Justice ( 6 items, $\alpha=.85$ ), respectively. Perceptions of truth were moderately and positively related to perceptions of justice, $r(98)=.43, p<.001$ 
Although we know of no existing scale for measuring participants' perceptions of a legal system's decisional accuracy with which to compare our Truth scale, participants' responses to the Justice scale were strongly associated with participants' responses to the individual item asking how fair they found the legal procedure, $r(98)=.65, p<.001$, which suggests that the Justice scale measured perceptions of procedural justice.

\section{Study 1}

To investigate whether the relationship between people's perceptions of truth and justice depend on the legal procedure to which they are exposed, we manipulated whether participants were exposed to an adversarial procedure or an inquisitorial procedure and whether they were exposed to a civil case or a criminal case. We then measured participants' perceptions of the degree of truth provided by the procedure and the degree of justice that it provided.

\section{Predictions}

We derived two sets of hypotheses from past research. The first set describes the relationship between perceptions of truth and justice within each decision-making system. The second set addresses whether each decision-making system is associated more highly with truth or justice.

Within-Paradigm Hypotheses. Because biased advocates have the freedom to produce potentially biased evidence to the decision maker in the adversarial system, we predicted that participants would perceive the adversarial system as more just than it is accurate. Because in a pure inquisitorial system an unbiased decision maker produces the evidence at trial with little input from the parties, we hypothesized that participants would perceive the inquisitorial system as more accurate than it is just. 
Between-Paradigm Hypotheses. Because biased advocates produce evidence to the decision maker in the adversarial system but not in the pure inquisitorial system, we predicted that participants would perceive the inquisitorial system as more accurate than the adversarial system. Because parties in the adversarial system have more control over the evidence that they present to the decision maker than do parties in the inquisitorial system, we predicted that participants would perceive the adversarial system as more just than the inquisitorial system.

\section{Methods}

\section{Participants}

One hundred and ninety-seven American participants were recruited via the online participation service, Amazon Mechanical Turk, to participate in an online study in return for nominal payment. Participants were 54\% female, 77\% Caucasian, averaged 36.11 years of age (with a standard deviation of 11.98), and ranged from 19 to 66 years of age. Fifty-three percent of the sample had completed at least a college degree and the median income of the sample was between $\$ 30,000$ and $\$ 39,999$.

\section{Procedure and Measures}

Participants were randomly assigned to a procedure (adversarial vs. inquisitorial) $\mathrm{x}$ case type (civil vs. criminal) factorial design. Participants were told that researchers were gathering information about different procedures for resolving legal disputes. They then read about a hypothetical legal case.

Participants were randomly assigned to two different versions of the casecriminal and civil— to determine whether the predicted effects are generalizable across case types. In the criminal version of the case, the dispute involved whether an allergic 
reaction to a dog bite caused "severe damage" under the law to convict the defendant of a misdemeanor. In the civil version of the case, the dispute involved whether a drug manufacturer's product caused internal injuries.

All participants then read about a proposed legal procedure for resolving the dispute. In the adversarial condition, participants were told that the legal procedure allowed litigants to call their own witnesses and to present their evidence to the decision maker. Participants were also told that litigants under this procedure could select their own expert witness, pay for that witness, and were not required to inform the court of any experts that they had interviewed but declined to hire, in accordance with the procedure in the adversarial system in the United States. They were also told that the decision maker would make a decision on the merits of each party's presentation.

In the inquisitorial condition, participants were told that the decision maker would decide which witnesses would testify at the trial. Participants were also told that the court would, among other things, appoint an expert witness to testify regarding the scientific issues raised in the case, and that the witness would work independently of the plaintiff and the defendant. Participants were told that the decision maker would question all of the witnesses under this procedure and would then make its decision.

Participants next completed a series of comprehension checks. The comprehension checks consisted of several questions designed to measure whether the participants understood the procedure by which the various witnesses would be selected and examined. Participants could not advance in the survey until they answered these questions correctly. All participants answered the comprehension questions correctly and completed the survey. 
Participants then answered a series of questions, described in the pilot study, designed to measure their perceptions of how well the legal procedure would produce factually accurate decisions and the degree to which the procedure was just.

Before being debriefed, participants provided basic demographic information, including their age, gender, race, ethnicity, income, and political orientation. They were also asked whether they had ever spent time in a courtroom and in what capacity. Fifteen percent of participants had been a litigant or witness in a legal proceeding, $22 \%$ had been summoned for jury duty, and $23 \%$ had appeared in court for minor traffic violations. None of these variables, including participants' experience with the legal system, produced systematic effects across the dependent measures in our study and are not discussed further.

\section{Results}

Results are reported in two parts. First, we conducted a preliminary test to determine if we could pool the data from participants in our civil and criminal case conditions. We then examined participants' perceptions of truth and justice when they were exposed to different legal procedures.

\section{Preliminary Analysis}

A mixed-design analysis of variance (ANOVA) was conducted to analyze the data. The analysis included (a) two between-subjects factors: case type (criminal vs. civil) and procedure (adversarial vs. inquisitorial); and (b) one within-subjects factor, which captured participants' judgments of the amount of truth and the amount of justice produced by each procedure. As expected, a 2 (case type: criminal vs. civil) x 2 (procedure: adversarial vs. inquisitorial) x 2 (evaluation: truth vs. justice) ANOVA with 
repeated measures on the last variable revealed no main effect of case type, $F(1,193)=$ $3.52, p=.062, \eta_{p}^{2}=.02,{ }^{1}$ no interaction between case type and procedure, $F(1,193)=$ $0.11, p=.741, \eta_{p}^{2}=.00$, no interaction between case type and evaluation, $F(1,193)=$ $0.98, p=.322, \eta_{\mathrm{p}}^{2}=.01$, and (most importantly) no three-way interaction between case type, procedure, and evaluation, $F(1,193)=0.10, p=.754, \eta_{\mathrm{p}}^{2}=.00$. Thus, data from participants exposed to the civil case and data from participants exposed to the criminal case were combined.

\section{Main Analysis: Truth and Justice}

To test the hypothesis that perceptions of truth and justice would differ (a) within each decision-making procedure and (b) between decision-making procedures, we performed a 2 (procedure: adversarial vs. inquisitorial) x 2 (evaluation: truth vs. justice) ANOVA with repeated measures on the second variable. As predicted, the analysis revealed a significant interaction between evaluation and procedure, $F(1,195)=133.47$, $p<.001, \eta_{\mathrm{p}}^{2}=.41($ see Figure 1$)$.

Within-paradigm comparisons. Because we expected that participants exposed to an adversarial procedure would perceive it as less accurate than it is just, and because we expected that participants exposed to an inquisitorial procedure would perceive it as less just than it is accurate, we examined the nature of the interaction reported above when participants were exposed to an adversarial procedure and when they were exposed to an inquisitorial procedure.

An analysis of participants' perceptions when they were exposed to an adversarial dispute revealed a statistically significant effect of evaluation, $F(1,99)=32.74, p<.001$, $\eta_{\mathrm{p}}^{2}=.25$, such that evaluations of truth $(M=4.29, S D=1.52)$ were lower than 
participants' evaluations of justice $(M=4.87, S D=1.08)$. Thus, as predicted, participants perceived the adversarial procedure to be more just than it is accurate. ${ }^{2}$

Conversely, and as predicted, an analysis of participants' perceptions when they were exposed to an inquisitorial dispute revealed a statistically significant effect of evaluation, $F(1,96)=105.49, p<.001, \eta_{p}^{2}=.52$, such that evaluations of truth $(M=$ $5.19, S D=1.38)$ were higher than participants' evaluations of justice $(M=3.97, S D=$ 1.25). Thus, participants perceived the inquisitorial procedure to be more accurate than it is just.

Between-paradigm comparisons. Because we expected that (a) the adversarial procedure would be perceived as less accurate than the inquisitorial procedure, and (b) the inquisitorial procedure would be perceived as less just than the adversarial procedure, we next examined the nature of the interaction reported above in terms of participants' perceptions of truth and justice.

An analysis of participants' perceptions of decisional accuracy revealed a statistically significant effect of procedure, $F(1,195)=19.14, p<.001, \eta_{p}^{2}=.09$, such that participants perceived the adversarial system $(M=4.29, S D=1.50)$ as less accurate than the inquisitorial system $(M=5.19, S D=1.38)$.

Conversely, and as predicted, an analysis of participants' perceptions of procedural justice revealed a statistically significant effect of procedure, $F(1,195)=$ $29.29, p<.001, \eta_{\mathrm{p}}^{2}=.13$, such that participants perceived the inquisitorial system $(M=$ 3.97, $S D=1.25)$ as less just than the adversarial system $(M=4.87, S D=1.08)$.

\section{Discussion}


Although many of the effect sizes observed in Study 1 are modest, the findings suggest that participants' perceptions of the truth and justice provided by adversarial and inquisitorial procedures aligns with Thibaut and Walker's (1978) hypothesis that these systems prioritize different psychological goals. Participants exposed to an adversarial procedure perceived it to produce verdicts that were more just than they were accurate. Conversely, participants exposed to an inquisitorial procedure perceived it as producing verdicts that were more accurate than just. Moreover, a comparison of the adversarial and inquisitorial systems revealed that the adversarial system was perceived as providing less truth to litigants than did the inquisitorial system, whereas the inquisitorial system was perceived as providing less justice to litigants than did the adversarial system.

\section{Study 2}

Study 1 suggests that perceptions of the truth provided by legal procedures differ from perceptions of the justice that they provide. Study 1 focused on these perceptions independent of legal outcomes, but the purpose of these procedures, ultimately, is to facilitate a resolution to legal disputes. Study 2 addresses how outcome information moderates perceptions of the truth and justice provided by these procedures. It also proposes a mediator of outcome effects in disputes involving scientific evidence.

\section{Truth, Justice, and Outcome Favorability}

Outcome favorability can exert considerable influence over our perceptions, judgments, and behaviors (Brockner et al., 1997). It can moderate people's job performance (Smither et al., 1993), retaliation behavior (Latham \& Wexley, 1994), decision acceptance (Skitka, 2002), affect (Bies et al., 1993), and organizational citizenship (Farh et al., 1997; for a review, see Skitka, Winquist, \& Hutchinson, 2003). 
Little research exists, however, comparing how outcomes affect perceptions of truth and justice in adversarial and inquisitorial dispute paradigms.

Favorable outcomes generally produce greater perceptions of decisional accuracy (see, e.g., Brett \& Atwater, 2001; Halperin, Snyder, Schenkel, \& Houston, 1976). Although no studies have examined the role that outcomes have on perceptions of decisional accuracy across legal decision-making paradigms, studies examining verdict satisfaction can provide a useful proxy. Two studies have directly compared the inquisitorial and adversarial systems with respect to the effects of outcome favorability on verdict satisfaction. Austin et al. (1981) found a significant interaction between the procedure to which participants were exposed and the outcome they received in a simulated hit-and-run trial. Austin et al. reported that the interaction was driven by substantial "polarity within the adversarial condition[]" (p. 294), such that higher satisfaction was associated with favorable outcomes. Notably, the judgments from participants exposed to the inquisitorial procedure did not exhibit such polarity. Similarly, in a study in which participants stood trial for cheating in a laboratory experiment, although LaTour (1978) did not find a statistically significant interaction between procedure and outcome, the means for the adversarial and inquisitorial conditions exhibited a similar pattern. Participants in the adversarial condition appeared sensitive to outcome information with respect to their satisfaction judgments, while participants in the inquisitorial condition were not.

Studies that have examined the relationship between outcome information and perceptions of justice have done so primarily in non-legal contexts, in which researchers presented participants with a set of rules that vary in fairness (for a review, see Brockner 
\& Wiesenfeld, 1996; Skitka, Winquist, \& Hutchinson, 2003). To the extent that the adversarial legal paradigm is perceived by litigants as fairer than the inquisitorial system because participants perceive it to provide them with greater voice, respect, and control over the proceedings (see, e.g., Thibaut \& Walker, 1975; Tyler, 1988), these studies provide insight into the manner that outcomes affect perceptions of justice across decision-making procedures. One body of research suggests that perceptions of fairer procedures are influenced more heavily by outcomes than are less fair procedures. Specifically, researchers have found that preferences for a procedure and perceptions of its fairness are highest when a fair procedure is paired with a favorable outcome, while preferences for a procedure and perceptions of its fairness are lowest when a fair procedure is paired with an unfavorable outcome, a phenomenon called the frustration effect (Cohen, 1985; Folger, 1977; Folger et al., 1979; Greenberg \& Folger, 1983; Lind \& Tyler, 1988; Kulik \& Clark, 1993).

Other researchers, however, have found that outcomes have a greater effect on perceptions of procedural fairness when the procedures themselves are less fair (Brockner \& Weisenfeld, 1996). This may occur, however, only when the correctness of the outcome is ambiguous (Kulik \& Clark, 1993; van den Bos, Lind, Vermunt, \& Wilke, 1997). Moreover, it in unclear whether the outcome effects reported in these studies can generalize to legal contexts, where the stakes of winning and losing are higher.

Thus, although case-specific attributes may moderate these effects, the majority of the research on the impact of outcome favorability on people's perceptions of decisional accuracy and procedural justice suggests that judgments made under an adversarial 
procedure are more polarized in response to case outcomes than are judgments made under an inquisitorial procedure. Study 2 tests this hypothesis.

\section{Predictions for Study 2}

Main Analysis. Based on research examining verdict satisfaction and perceptions of fairness in non-legal contexts, we predict that participants will be more sensitive to outcomes in the adversarial condition than in the inquisitorial condition.

Mediation. We conducted a mediation analysis to determine the cause of any differences that emerge with respect to the effects of legal outcome on perceptions of truth and justice. Past research suggests that policymakers have become concerned about the presence of "hired gun" expert witnesses that testify in cases involving scientific evidence in the adversarial system, because citizens perceive these experts as non-neutral and whose testimony is "for sale" (Cooper \& Neuhaus, 2000; Saks \& Wissler, 1984; Saks \& VanDuizend, 1983). No one has yet examined whether the presence of these nonneutral, "hired gun" experts affects citizens' perceptions of the truth and justice produced by the adversarial system compared to the inquisitorial system, where parties generally cannot hire their own expert witnesses. The number of legal cases that require scientific expertise continues to grow in the United States, which makes this variable an important theoretical and practical mediator to examine in the context of our vignette, which involved a scientific case (see, e.g., Saks \& Wissler, 1984). We thus predicted that the perceived neutrality of the expert witness would mediate the relationship between the outcome participants received and their assessments of the procedure's truth and justice in the adversarial system, but not in the inquisitorial system.

\section{Methods}




\section{Participants}

One hundred and sixty-five American participants were recruited online through Amazon Mechanical Turk and received nominal payment to participate in an online study. Participants were 52\% female, $80 \%$ Caucasian, averaged 37.61 years of age $($ standard deviation $=11.72)$ and ranged from 19 to 70 years of age. Fifty-five percent of the sample had completed at least a college degree, and the median income of the sample was between $\$ 40,000$ and $\$ 49,999$.

\section{Procedure and Measures}

Participants read a case in which they were asked to imagine that they had taken a defendant corporation's blood pressure drug, experienced violent stomach pains that left them hospitalized, and sued the defendant in a civil proceeding for monetary damages. Identical expert testimony was revealed in all experimental conditions. In the adversarial condition, facts were revealed through direct- and cross- examination of the expert. In the inquisitorial condition, the expert relayed the same facts through one examination by the judge.

Participants were randomly assigned to one of two outcome conditions. In the favorable outcome condition, participants were told that the decision maker deliberated and found in their favor. In the unfavorable outcome condition, participants were told that the decision maker deliberated and found in favor of the drug manufacturer.

Participants then answered questions, as they did in Study 1, to measure their impressions of the truth and justice provided by these decision-making procedures. Additionally, for the purpose of a mediation analysis, participants were asked three questions designed to measure the degree to which they perceived the expert witness to 
be neutral: "How motivated were the experts to give testimony that was not slanted toward one party?"; "How motivated were the experts to testify truthfully?"; and "How motivated were the expert witnesses to be unbiased?" To ensure that these items were not simply additional components of our justice measure, we conducted a principal component analysis with an oblique rotation in which we included these three items. The analysis revealed three factors: the truth items loaded onto one factor, the justice items loaded onto a second factor, and the expert neutrality items loaded onto a third factor with factor loadings above .85 . The items measuring expert neutrality were averaged to form an expert neutrality scale (3 items, $\alpha=.92$ ).

Finally, participants were asked demographic questions and were debriefed. As in Study 1, they also were asked whether they had ever spent time in a courtroom and in what capacity. Seventeen percent of participants had been a litigant or witness in a legal proceeding, $27 \%$ had been summoned for jury duty, and $22 \%$ had appeared in court for minor traffic violations. As in Study 1, none of these variables, including participants' experience with the legal system, produced systematic effects across the dependent measures in our study and are not discussed further.

\section{Results}

Results are reported in two parts. First, we conducted the main analysis, in which we examined participants' perceptions of the truth and justice produced by adversarial and inquisitorial procedures when they were exposed to different legal outcomes. Second, we conducted a mediation analysis to determine the pathway between the outcome that participants received and their perceptions of truth and justice.

\section{Main Analysis: Truth and Justice}


As in Study 1, a mixed-design analysis of variance (ANOVA) was conducted to analyze the data. The analysis included (a) two between-subjects factors: procedure (adversarial vs. inquisitorial) and outcome (favorable vs. unfavorable); and (b) one within-subjects factor, which captured participants judgments of the amount of truth and the amount of justice produced by each procedure. To test the hypothesis that the outcome of the dispute would affect participants' perceptions of truth and justice depending on the legal paradigm to which they were exposed, we conducted a 2 (procedure: adversarial vs. inquisitorial) x 2 (outcome: favorable vs. unfavorable) x 2 (evaluation: truth vs. justice) ANOVA with repeated measures on the last variable. As predicted, the analysis revealed a main effect of outcome, such that participants' evaluations of truth and justice were higher when they received a favorable outcome $(M=$ $4.77, S D=1.48)$ than when they received an unfavorable outcome $(M=4.35, S D=1.38)$, $F(1,161)=6.55, p=.011, \eta_{p}^{2}=.04$

This main effect was qualified by two significant two-way interactions. First, the analysis revealed an interaction between evaluation and procedure, $F(1,161)=42.37, p<$ $.001, \eta_{p}^{2}=.21$, which replicates the results we found in Study 1 . When we examined within-paradigm effects, we found that participants rated the adversarial system as more just $(M=4.76, S D=1.38)$ than it was accurate $(M=4.43, S D=1.46), F(1,85)=8.77, p$ $=.004, \eta_{\mathrm{p}}^{2}=.09$, and they rated the inquisitorial system as more accurate $(M=5.01, S D$ $=1.36)$ than it was just $(M=4.27, S D=1.45), F(1,78)=40.87, p<.001, \eta_{\mathrm{p}}^{2}=.34$. When we examined between-paradigm effects, we found that the adversarial procedure $(M=4.76, S D=1.38)$ was perceived to be more just than the inquisitorial procedure $(M$ $=4.27, S D=1.45), F(1,163)=4.89, p=.028, \eta_{\mathrm{p}}^{2}=.03$, and the inquisitorial procedure 
$(M=5.01, S D=1.36)$ was perceived to be more accurate than the adversarial procedure $(M=4.43, S D=1.46), F(1,163)=7.08, p=.009, \eta_{\mathrm{p}}^{2}=.04$.

Second, and as expected, the analysis revealed a significant interaction between the procedure to which participants were exposed and the outcome they received, $F(1$, $161)=6.42, p=.012, \eta_{p}^{2}=.04$ (see Figure 2$) .^{3}$ Because we found no three-way interaction, $F(1,161)=0.07, p=.799, \eta_{p}^{2}=.00$, and because we hypothesized that outcome favorability would affect participants' perceptions of the legal system differently across procedural conditions, we investigated this interaction by examining the effects of outcome when participants were exposed to an adversarial system and when they were exposed to an inquisitorial system.

When participants were exposed to an adversarial system, they evaluated the system as producing more truth and justice when they received a favorable outcome $(M=$ $5.21, S D=1.25)$ than when they received an unfavorable outcome $(M=4.19, S D=1.21)$, $F(1,84)=14.30, p<.001, \eta_{\mathrm{p}}^{2}=.15$. In contrast, the outcome that participants received did not affect their evaluations of the inquisitorial system $\left(M_{\text {Favorable }}=4.65, S D_{\text {Favorable }}=\right.$ $\left.1.35 ; M_{\text {Unfavorable }}=4.64, S D_{\text {Unfavorable }}=1.30\right), F(1,77)=0.00, p=.987, \eta_{\mathrm{p}}^{2}=.00$. Thus, as predicted, participants' evaluations of the adversarial system were affected by the outcome that they received, whereas the outcome did not affect participants' evaluations of the inquisitorial system.

\section{Mediated Moderation Analysis}

To understand the reason why the legal outcome and legal procedure to which participants were exposed affected their evaluations of the procedure in the adversarial condition but not in the inquisitorial condition, we performed a mediation analysis with 
respect to their evaluations of the expert witness involved in the case. Because the perceived truth and justice that these procedures produce are separate constructs, we performed the mediation analysis on these dependent variables separately.

Perceptions of Truth. We first tested whether the interactive effect of legal outcome and legal procedure predicted participants' perceptions of the truth produced by the procedure. In the first model, we included (a) legal outcome, legal procedure, and their interactive effect as predictor variables and (b) perceptions of truth as the dependent variable. Linear regression analysis revealed that the interactive effect of legal outcome and legal procedure on participants' perceptions of truth was statistically significant, $b=$ $0.98, S E=0.43, p=.025$, such that favorable legal outcomes were associated with increases in perceptions of truth when participants were exposed to an adversarial procedure, $b=1.09, S E=0.30, p<.001$, but not when they were exposed to an inquisitorial procedure, $b=0.11, S E=0.31, p=.725$ (see Figure 3).

We then constructed a second model in which we included (a) legal outcome, legal procedure, and their interactive effect as predictor variables and (b) the expert's perceived neutrality (centered) as the dependent variable. A linear regression revealed that the interactive effect of legal outcome and legal procedure on perceptions of the expert's neutrality was statistically significant, $b=1.22, S E=0.49, p=.014$. Participants exposed to an adversarial procedure perceived the expert as less objective when they received a less favorable outcome, $b=-1.14, S E=0.36, p=.002$, whereas participants exposed to an inquisitorial procedure did not, $b=0.08, S E=0.33, p=.820$.

Finally, we constructed a third model, in which we included as predictor variables the following: (a) legal outcome, legal procedure, the interactive effect of legal outcome 
and legal procedure in one block and (b) perceptions of the expert's neutrality in a second block. We included perceptions of truth as the dependent variable. Higher ratings of the expert's neutrality were associated with higher ratings of perceived truth, $b=0.39, S E=$ $0.07, p<.001$. Most importantly, and as predicted, the interaction between legal outcome and legal procedure on perceptions of truth became non-significant when ratings of the expert's neutrality were added to the model, $b=0.63, S E=0.43, p=.138$. Thus, as confirmed by bootstrapping analysis (Preacher \& Hayes, 2004), ${ }^{4}$ perceptions of an expert's neutrality fully mediated the effect of outcome and legal procedure on participants' perceptions of truth, $b=0.48, S E=0.23,95 \% \mathrm{CI}[0.06,0.97]$.

Perceptions of Justice. We performed a similar mediation analysis on participants' perceptions of justice. In the first model, the analysis revealed that the interactive effect of legal outcome and legal procedure was statistically significant, $b=$ $1.06, S E=0.44, p=.016$, such that participants exposed to an adversarial procedure perceived the procedure to be less just when they received a negative outcome, $b=-0.96$, $S E=0.31, p=.002$, while participants exposed to an inquisitorial procedure did not, $b=$ $0.09, S E=0.31, p=.752$ (see Figure 4).

When we examined expert neutrality as the dependent variable, the regression revealed that the interactive effect of legal outcome and legal procedure on perceptions of the expert's neutrality was statistically significant, $b=1.22, S E=0.49, p=.014$. Participants exposed to an adversarial procedure perceived the expert as less objective when they received a less favorable outcome, $b=-1.14, S E=0.36, p=.002$, whereas participants exposed to an inquisitorial procedure did not, $b=0.08, S E=0.33, p=.82$. 
Finally, in a regression model that included expert neutrality as a predictor variable in a second block, the analysis revealed that higher ratings of the expert's neutrality were associated with higher ratings of perceived justice, $b=0.35, S E=0.07, p$ $<.001$. Most importantly, and as predicted, the interaction between legal outcome and legal procedure on perceptions of justice became non-significant when ratings of the expert's neutrality were added to the model, $b=0.73, S E=0.44, p=.103$. As confirmed by bootstrapping analysis, perceptions of an expert's neutrality fully mediated the effect of outcome and legal procedure on participants' perceptions of justice, $b=0.43, S E=$ $0.20,95 \%$ CI $[0.07,0.86]$.

The mediated moderation analysis revealed stark contrasts. For participants who experienced an adversarial procedure, the outcome they received influenced their perceptions of the expert witness's neutrality, which was also associated with their perceptions of both the truth and justice provided by the adversarial procedure. The effects were different for participants who experienced an inquisitorial procedure. Although their perceptions of the expert witness's neutrality was associated with their perceptions of the truth and justice provided by the inquisitorial procedure, the outcome they received did not influence their perceptions of the expert witness's neutrality.

\section{Discussion}

Study 2 extended the findings of Study 1 by examining the moderating role of outcome favorability on litigants' perceptions of truth and justice. As predicted, the outcome of a legal dispute affected participants' evaluations of the adversarial system, although the size of the effect was modest. Figure 2 illustrates the polarity in participants' evaluations of the adversarial procedure: favorable outcomes in the 
adversarial system produced the highest evaluations of the procedure and unfavorable outcomes in the adversarial system produced the lowest evaluations. This is consistent with a frustration effect, whereby preferences for a procedure and perceptions of its fairness are highest when a fair procedure is paired with a favorable outcome, while preferences for a procedure and perceptions of its fairness are lowest when a fair procedure is paired with an unfavorable outcome (Cohen, 1985; Folger, 1977; Folger et al., 1979; Greenberg \& Folger, 1983; Lind \& Tyler, 1988; Kulik \& Clark, 1993). No such polarity was found for judgments made after exposure to the inquisitorial system.

A mediated moderation analysis supports our hypothesis that in cases involving scientific evidence in the adversarial system, perceptions of the expert witness's neutrality mediated the relationship between the outcome participants received and their perceptions of truth and justice. Participants perceived these party-proffered experts as non-neutral when they received unfavorable outcomes compared to the court-appointed experts to which participants were exposed in the inquisitorial system.

\section{General Discussion}

Two studies reveal that litigants' perceptions of the adversarial and inquisitorial legal systems are consistent with Thibaut and Walker's (1978) theory that these systems prioritize different psycholegal goals. The studies reported here confirm that in the context of scientific disputes, there are several statistically significant differences in the way these decision-making paradigms are perceived by potential litigants. Potential litigants perceive the adversarial paradigm as producing less accurate verdicts in these cases than it does verdicts that are just, and they perceive the adversarial paradigm as producing more justice in these cases than does the inquisitorial paradigm. Conversely, 
litigants perceive the inquisitorial paradigm as producing more truth than it produces justice, and they perceive the inquisitorial paradigm as producing more truth than does the adversarial paradigm.

The favorability of the outcomes that participants receive moderates these perceptions. Ratings of the truth and justice produced by the adversarial system exhibited polarity in ways consistent with past literature: when participants received a favorable outcome, their perceptions of the truth and justice provided by the adversarial procedure increased, and when they received an unfavorable outcome, their perceptions decreased. Notably, as illustrated in Figure 3, when participants in the adversarial condition received a favorable outcome, perceptions of the truth produced by the adversarial system increased to levels that are statistically similar to the perceptions of truth produced by the inquisitorial system. As illustrated in Figure 4, when participants in the adversarial condition received an unfavorable outcome, perceptions of the justice produced by the adversarial system decreased to levels that are statistically similar to the perceptions of justice produced by the inquisitorial system. In contrast, we observed no polarity in participants' perceptions of the truth or justice provided by the inquisitorial procedure in response to case outcomes.

Several implications flow from these findings. Scholars of dispute systems are currently investigating the merits of adversarial and inquisitorial dispute resolution paradigms (Anderson \& Otto, 2003; Block \& Parker, 2004; Dewatripont \& Triole, 1999; Finegan, 2009; Kessler, 2005; MacCoun, 1998; Moohr, 2004; Mosteller, 2011; Parisi, 2002; Roach, 2010; Van Koppen \& Penrod, 2003; Wolfe \& Proszek, 1997). The studies reported here suggest that, in the context of disputes over scientific evidence, the 
inquisitorial system can claim some clear advantages over the adversarial system — for example, a perception of greater accuracy and less sensitivity to outcome informationbut these advantages do come at the cost of perceived fairness, at least among these respondents. Future research might identify other underlying mechanisms that cause litigants in the adversarial system to be more sensitive to outcome information compared to litigants in the inquisitorial system. For example, does the act of producing one's own evidence to the decision maker cause participants to become more invested in the outcome of a dispute than if they do not have the ability to produce their own evidence? Although we might hypothesize that people who have spent resources filing a lawsuit will be invested in the outcome of the lawsuit regardless of the procedure used to resolve it, researchers have found that perceptions of voice have powerful effects on perceptions of dispute systems (for a review, see Tyler \& Markell, 2010).

It is also possible that American participants may have felt less invested in the inquisitorial system in our study because they are less familiar with that legal system. This, in turn, might have made them less sensitive to favorable and unfavorable outcomes in the inquisitorial condition. We know of no published studies that have shown that unfamiliarity with a legal procedure leads to lower investment in that procedure, but future researchers should examine this potential explanation.

Future research might also examine individual difference variables that predict preferences for adversarial or inquisitorial procedures. To the extent that the inquisitorial system is associated with decisional accuracy, individuals high in ambiguity intolerance and in the need for cognitive closure may prefer that procedure to the adversarial procedure (see Budner, 1962; Kruglanski \& Webster, 1994). Similarly, individuals high 
in moral self-identity might prefer the adversarial procedure, which participants in this study associated with justice (Aquino \& Reed, 2002).

Further, in light of Anderson and Otto's (2003) research that Dutch participants and American participants each preferred their home country's decision making system, researchers should test whether the findings reported here-in which American participants perceived the adversarial system to produce more justice than the inquisitorial system and vice-versa with respect to their perceptions of accuracyreplicate to samples of participants from other countries.

The results reported here also have implications for scholars of juries and courts. Disputes involving scientific evidence routinely involve the testimony of expert witnesses. The mediated moderation analysis reported here suggests that perceptions of the neutrality of these experts are associated with litigants' perceptions of the adversary system. Research in this vein is expanding (see, e.g., Brekke, Enko, Clavet, \& Seelau, 1991; Cooper \& Neuhaus, 2000) and should focus, for example, on determining the ways in which policymakers can mitigate the perception that hired-gun experts affect the accuracy of verdicts produced by the adversarial system (see, e.g., Saks \& Van Duizend, 1983).

The current study is subject to limitations. In vignette studies, it is always difficult to gauge the degree of attention put forth by participants and the degree to which they truly imagined being a litigating plaintiff, as participants did in Study 2. Safeguards were put in place to account for this, to some degree, by including attention checks and comprehension checks. In addition, we examined the data for obvious cases of suspect responses - for example, answering "strongly disagree" for every item in the study —and 
found no data to exclude. Nonetheless, reading about a legal proceeding in a vignette study is a different psychological experience than actually being involved in litigation. Especially in light of the small effect sizes found in the studies reported here, future research should attempt to replicate the results obtained here in a field study with greater ecological validity. Measuring the perceptions of real litigants would be beneficial to our understanding of how these legal systems are perceived "from the inside."

The manner in which we measured procedural justice merits some caution as well. Many studies have measured procedural justice by examining the degree to which participants experience its components, such as their perceptions of the degree of respect they received, the degree of control they believe they had during the proceedings, and the perceived neutrality of the decision maker (see, e.g., Tyler, 1988; Tyler \& Lind, 1992; Tyler \& Markell, 2010). Other researchers, however, measure procedural justice by explicitly asking participants to quantify the degree to which they were treated fairly (see, e.g., Folger, 1977), because equating a construct to its antecedents may lead to an inaccurate measurement of the construct. Moreover, although research suggests that perceptions of procedural justice and satisfaction with those procedures are separate psychological constructs (see, e.g., Adler, Hensler \& Nelson, 1983; Lind \& Tyler, 1988), we cannot fully eliminate the possibility that our justice measure also measured satisfaction.

Finally, in practice, inquisitorial decision makers exhibit variation with respect to the degree of control they exercise over legal proceedings (see, e.g., Sheppard, 1985). Because this study is the first to compare participants' perceptions of the truth and justice produced by adversarial and inquisitorial legal systems, we tested these perceptions in the 
context of a "pure" adversarial system and a "pure" inquisitorial system, where participants experienced clear differences in the amount of voice and control that they had in the proceedings. By examining participants' perceptions of truth and justice at the "outer boundaries" along the continuum that exists between adversarial and inquisitorial procedures, our construction of the inquisitorial model was necessarily simplified. Future research should examine whether differences in perceptions of truth and justice exist with respect to hybrid adversarial and inquisitorial models.

The question of which legal procedure is "better" for resolving social disputes is a difficult one that has generated substantial scholarly inquiry. This might be the wrong question to ask, however, because litigants perceive these different legal procedures to prioritize different psycholegal goals, such as the pursuit of truth and the pursuit of justice (Crombag, 2003; Thibaut \& Walker, 1978). Continued research into litigants' perceptions of these procedures can assist policymakers in creating dispute systems that align more closely with the policy preferences of their citizens. 


\section{References}

Adler, J., Hensler, D., \& Nelson, C. (1983). Simple Justice: How Litigants Fare in the Pittsburgh Court Arbitration Program. Santa Monica, CA: RAND Corporation.

Anderson, R. A. \& Otto, A. L. (2003). Perceptions of fairness in the justice system: A cross-cultural comparison. Social Behavior and Personality, 31, 557-564.

Aquino, K. F. \& Reed, A. (2002). The self-importance of moral identity. Journal of Personality and Social Psychology, 83, 1423-1440.

Austin, W. \& Tobiasen, J. M. (1984). Legal justice and the psychology of conflict resolution. In R. Folger (Ed.), The Sense of Injustice (pp. 227-274). New York: Plenum Press.

Berinsky, A. J., Huber, G. A., \& Lenz, G. S. (2012). Evaluating online labor markets for experimental research: Amazon.com's Mechanical Turk. Political Analysis, 20, 351-368.

Block, M. K. \& Parker, J. S. (2004). Decision making in the absence of successful fact finding: Theory and experimental evidence on adversarial versus inquisitorial systems of adjudication. International Review of Law and Economics, 24, 89105.

Bies, R. J., Martin, C. L., \& Brockner, J. (1993). Just laid off, but still a “good citizen”? Only if the process is fair. Employee Responsibilities Rights Journal, 6, 227-238.

Brekke, N. J., Enko, P. J., Clavet, G., \& Seelau, E. (1991). Of juries and court-appointed experts: The impact of nonadversarial versus adversarial expert testimony. Law and Human Behavior, 15, 451-475. 
Brett, J., \& Atwater, L. (2001). 360-degree feedback: Accuracy, reactions and perceptions of usefulness. Journal of Applied Psychology, 86, 930-942.

Brockner, J., Siegel, P. A., Daly, J. P., Tyler, T., \& Martin, C. (1997). When trust matters: The moderating effect of outcome favorability. Administrative Science Quarterly, 42, 558-583.

Brockner, J., \& Wiesenfeld, B. M. (1996). An integrative framework for explaining reactions to decisions: The interactive effects of outcomes and procedures. Psychological Bulletin, 120, 189-208.

Budner, S. (1962). Intolerance of ambiguity as a personality variable. Journal of Personality, 30, 29-50.

Buhrmester, M., Kwang, T., \& Gosling, S. D. (2011). Amazon's Mechanical Turk: A new source of inexpensive, yet high-quality, data? Perspectives on Psychological Science, 6, 3-5.

Cohen, R. L. (1985). Procedural justice and participation. Human Relations, 38, 643663.

Cooper, J. \& Neuhaus, I. (2000). The "hired gun" effect: Assessing the effect of pay, frequency of testifying, and credentials on the perceptions of expert testimony. Law and Human Behavior, 24, 149-171.

Crombag, H. F. M. (2003). Adversarial or inquisitorial: Do we have a choice?, In P. J. Van Koppen \& S. D. Penrod (Eds.), Adversarial versus Inquisitorial Justice: Psychological Perspectives on Criminal Justice Systems (pp. 21-25). New York: Springer Science+Business Media. 
Damaska, M. R. (1973). Evidentiary barriers to conviction and two models of criminal procedure: A comparative study. University of Pennsylvania Law Review, 121, 506-589.

Dewatripont, M. \& Trirole, J. (1999). Advocates. Journal of Political Economy, 107, 139.

Farh, J.-L., Earley, P. C., \& Lin, S.-C. (1997). Impetus for action: A cultural analysis of justice and organizational citizenship behavior in Chinese society. Administrative Science Quarterly, 42, 421-444.

Finegan, S. (2009). Pro se criminal trials and the merging of inquisitorial and adversarial systems of justice. Catholic University Law Review, 58, 445-499.

Folger, R., Rosenfield, D., Grove, J., \& Corkran, L. (1979). Effects of "voice" and peer opinions on responses to inequity. Journal of Personality and Social Psychology, $37,2243-2261$.

Folger, R. (1977). Distributive and procedural justice: Combined impact of "voice" and improvement on experienced inequity. Journal of Personality and Social Psychology, 35, 108-119.

Greenberg, J. \& Folger, R. (1983). Procedural justice, participation, and the fair process effect in groups and organizations. In P. B. Paulus (Ed.), Basic Group Processes (pp. 235-256). New York: Springer-Verlag.

Guthrie, C., Rachlinski, J. J., \& Wistrich, A. J. (2001). Inside the judicial mind. Cornell Law Review, 86, 777-830. 
Halperin, K., Snyder, C. R., Schenkel, R. J., \& Houston, B. K. (1976). Effect of source status and message favorability on acceptance of personality feedback. Journal of Applied Psychology, 61, 85-88.

Hayden, R. \& Anderson, J. (1979). On the evaluation of procedural systems in laboratory experiments: A critique of Thibaut and Walker, Law and Human Behavior, 3, 21-38.

Houlden, P., LaTour, S., Walker, L., \& Thibaut, J. (1978). Preference for modes of dispute resolution as a function of process and decision control. Journal of Experimental Social Psychology, 14, 13-30.

Kessler, A. D. (2005). Our inquisitorial tradition: Equity procedure, due process, and the search for an alternative to the adversarial. Cornell Law Review, 90, 1181-1275.

Kulik, C. T. \& Clark, S. C. (1993). Frustration effects in procedural justice research: The case of drug-testing litigation. Social Justice Research, 6, 287-299.

Landsman, S. \& Rakos, R. F. (1994). A preliminary inquiry into the effect of potentially biasing information on judges and jurors in civil litigation. Behavioral Sciences \& the Law, 12, 113-126.

Latham, G. P. \& Wexley, K. N. (1994). Increasing Productivity through Performance Appraisal. Reading, MA: Addison Wesley.

LaTour, S., Houlden, P., Walker, L., \& Thibaut, J. (1976). Some determinants of preference for modes of conflict resolution. Journal of Conflict Resolution, 20, 319-356.

Lind, E. A., Thibaut, J., \& Walker, L. (1973). Discovery and presentation of evidence in adversary and nonadversary proceedings. Michigan Law Review, 71, 1129-1144. 
Lind, E. A. \& Tyler, T. R. (1988). The Social Psychology of Procedural Justice. New York: Plenum Press.

Lind, E. A. \& Walker, L. (1979). Theory testing, theory development, and laboratory research on legal issues. Law and Human Behavior, 3, 5-20.

MacCoun, R. J. (1998). Biases in the interpretation and use of research results. Annual Review of Psychology, 49, 259-287.

Mason, W. \& Suri, S. (2010). Conducting behavioral research on Amazon's Mechanical Turk. Behavioral Research Methods, 44, 1-23.

Moohr, G. S. (2004). Prosecutorial power in an adversarial system: Lessons from current white collar cases and the inquisitorial model. Buffalo Criminal Law Review, 8, 165-220.

Mosteller, R. P. (2011). Failures of the American adversarial system to protect the innocent and conceptual advantages in the inquisitorial design for investigative fairness. North Carolina Journal of International Law and Regulation, 36, 319364.

Parisi, F. (2002). Rent-seeking though litigation: Adversarial and inquisitorial systems. International Review of Law and Economics, 22, 193-214.

Preacher, K. J. \& Hayes, A. F. (2004). SPSS and SAS procedures for estimating indirect effects in simple mediation models. Behavior Research Methods, Instruments, \& Computers, 36, 717-731.

Roach, K. (2010). Wrongful convictions: Adversarial and inquisitorial themes. North Carolina Journal of International Law and Commercial Regulation, 35, 387-446. 
Rosenberg, M., Weinstein, J., Smit, H., \& Korn, H. L. (1976). Elements of Civil Procedure. New York: Univ. Casebook Series.

Saks, M. J., \& Van Duizend, R. (1983). The Use of Scientific Evidence in Litigation. Williamsburg, VA: National Center for State Courts.

Saks, M. J., \& Wissler, R. L. (1984). Legal and psychological bases of expert testimony: Surveys of the law and of jurors. Behavioral Sciences and the Law, 2, 435-449.

Sheppard, B. H. (1985). Justice is no simple matter: Case for elaborating our model of procedural fairness. Journal of Personality and Social Psychology, 49, 953-962.

Sheppard, B. H., \& Vidmar, N. (1980). Adversary pretrial procedures and testimonial evidence: Effects of lawyer's role and Machiavellianism. Journal of Personality and Social Psychology, 39, 320-332.

Skitka, L. J. (2002). Do the means always justify the ends or do the ends sometimes justify the means? A value protection model of justice reasoning. Personality and Social Psychology Bulletin, 28, 588-597.

Skitka, L. J., Winquist, J. \& Hutchinson, S. (2003). Are outcome fairness and outcome favorability distinguishable psychological constructs? A meta-analytic review. Social Justice Research, 16, 309-341.

Smither, J. W., Reilly, R. R., Millsap, R. E., Pearlman, K., \& Stoffey, R. W. (1993). Applicant reactions to selection procedures. Personnel Psychology, 46, 49-76.

Thibaut, J. \& Walker, L. (1978). A theory of procedure. California Law Review, 66, 541-566.

Thibaut, J. \& Walker, L. (1975). Procedural Justice: A Psychological Analysis. Hillsdale, NJ: Erlbaum. 
Thibaut, J., Walker, L., \& Lind, E. A. (1972). Adversary presentation and bias in legal decisionmaking. Harvard Law Review, 86, 386-401.

Tyler, T. R. (2006). Why People Obey the Law: Procedural Justice, Legitimacy, and Compliance. Princeton, NJ: Princeton Univ. Press.

Tyler, T. R. (2000). Social justice: Outcome and procedure. International Journal of Psychology, 35, 117-125.

Tyler, T. R. (1988). What is procedural justice?: Criteria used by citizens to assess the fairness of legal procedures. Law and Society Review, 22, 103-135.

Tyler, T. R. (1987). The psychology of procedural justice: A test of the group-value model. Journal of Personality and Social Psychology, 57, 830-838.

Tyler, T. R. \& Lind, E. A. (1992). A relational model of authority in groups. Advances in Experimental Social Psychology, 25, 115-191.

Tyler, T. R. \& Markell, D. (2010). The public regulation of land-use decisions: Criteria for evaluating alternative procedures. Journal of Empirical Legal Studies, 7, 538573.

Van den Bos, K., Lind, E. A., Vermunt, R., \& Wilke, H. A. M. (1997). How do I judge my outcome when I do not know the outcome of others? The psychology of the fair process effect. Journal of Personality and Social Psychology, 72, 1034-1046.

Van Koppen, P. J. \& Penrod, S. D. (2003). Adversarial or inquisitorial: Comparing systems. In P. J. Van Koppen \& S. D. Penrod (Eds.), Adversarial versus Inquisitorial Justice: Psychological Perspectives on Criminal Justice Systems (pp. 1-19). New York: Springer Science+Business Media. 
Walker, L., LaTour, S., Lind, E. A., \& Thibaut, J. (1974). Reactions to participants and observers to modes of adjudication. Journal of Applied Social Psychology, 4, 295-310.

Webster, D. M., \& Kruglanski, A. W. (1994). Individual differences in need for cognitive closure. Journal of Personality and Social Psychology, 67, 1049-1062

Wendorf, S. A. \& Firestone, I. J. (1999, Aug.). Social justice and moral reasoning: An empirical integration of two paradigms in psychological research. Paper presented at the 107th Annual Meeting of the APA, Boston, MA. Retrieved from http://www4.uwsp.edu/psych/cw/research/wendorf-moraljustice.pdf.

Wolfe, J. S. \& Proszek, L. B. (1997). Interaction dynamics in federal administrative decision making: The role of the inquisitorial judge and the adversarial lawyer. Tulsa Law Journal, 33, 293-347. 


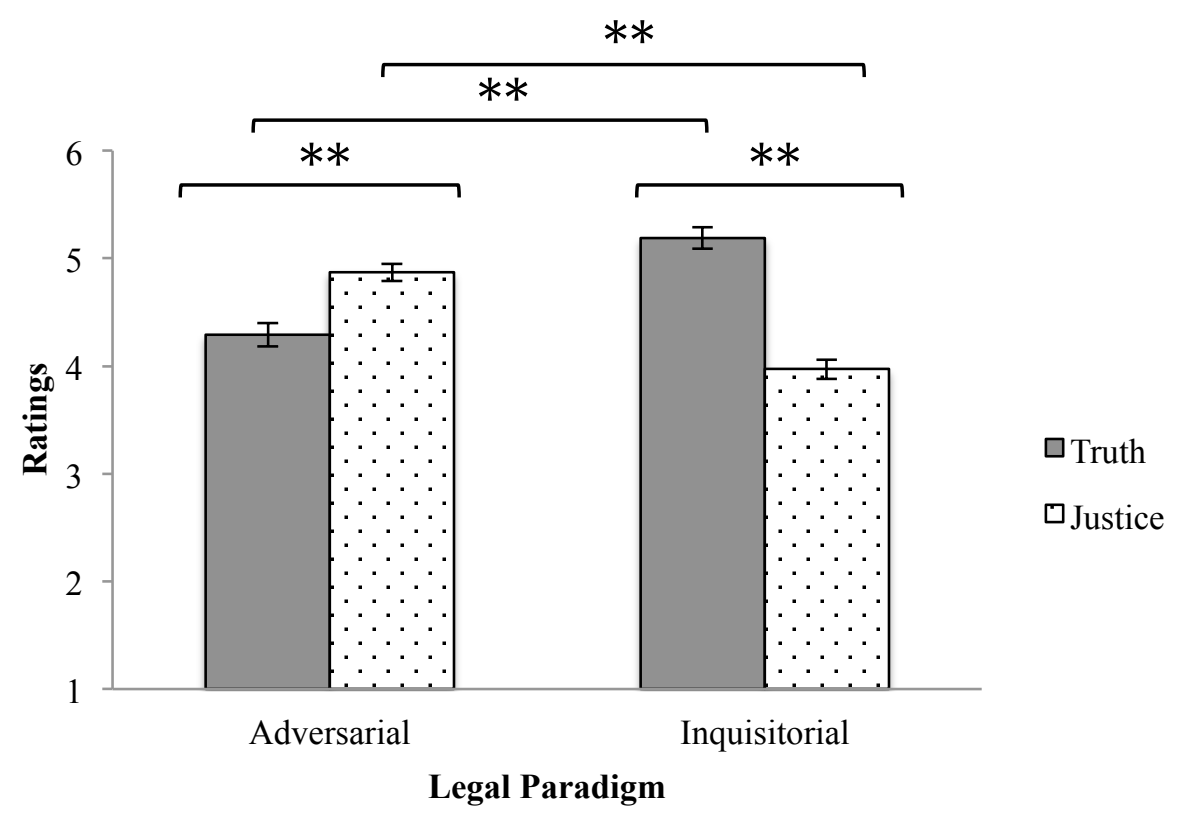

Figure 1. Perceptions of truth and justice as a function of legal procedure. Error bars represent standard errors of the mean. Effect sizes $\left(\eta_{p}^{2}\right)$ are as follows: (a) for the interaction between evaluation and legal procedure: .41; (b) for the within-paradigm effect of evaluation in the adversarial system: .25; (c) for the within-paradigm effect of evaluation in the inquisitorial system: .52; (d) for the between-paradigm effect of legal procedure with respect to perceptions of truth: .09; and (e) for the between paradigmeffect of legal procedure with respect to perceptions of justice: .13.

$* *$ denotes $p<.001$. 


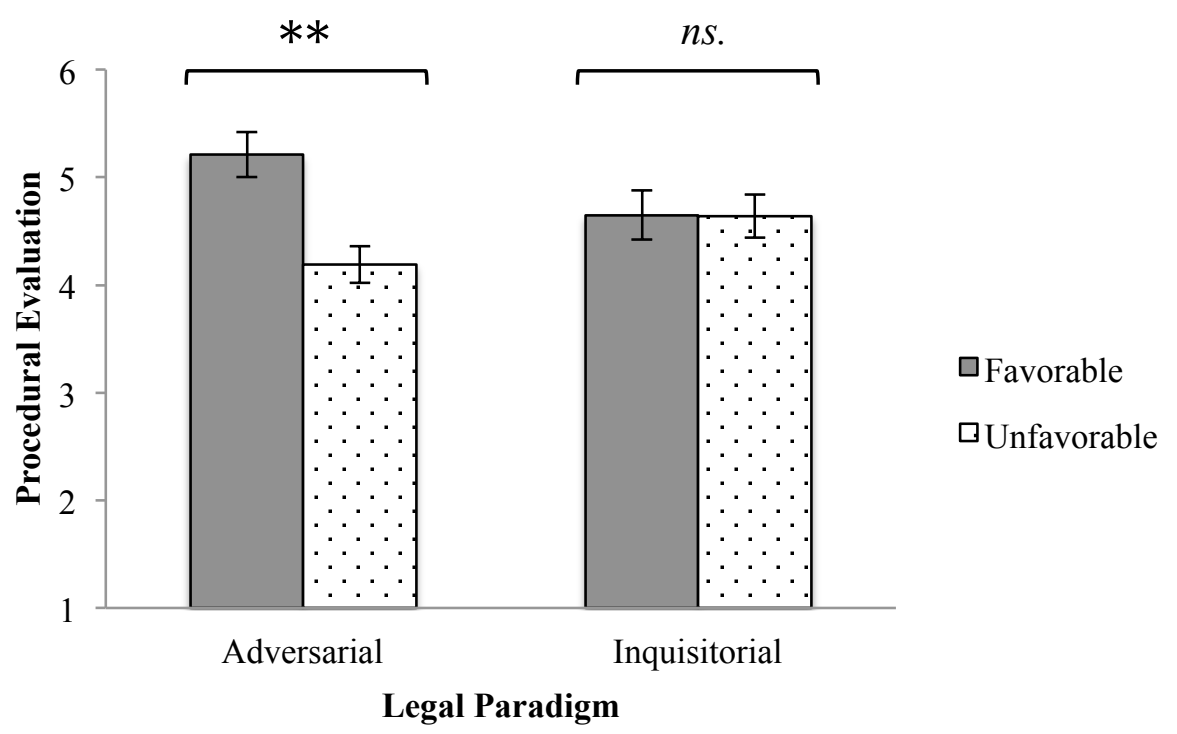

Figure 2. Evaluations of truth and justice (as a composite variable) as a function of legal outcome and decision making paradigm. Error bars represent standard errors of the mean. Effect sizes $\left(\eta_{p}^{2}\right)$ are as follows: (a) for the interaction between legal procedure and outcome: .04; and (b) for the effect of outcome in the adversarial system: .15. $* *$ denotes $p<.001$. 


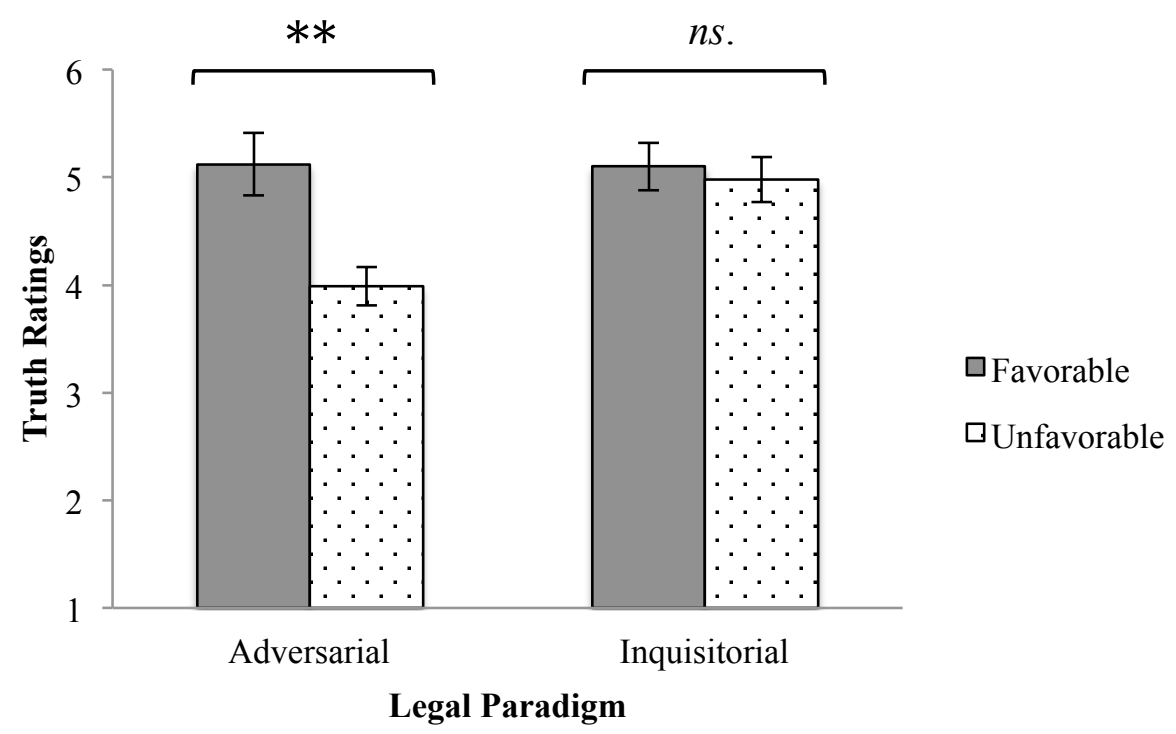

Figure 3. Perceptions of truth as a function of legal procedure and outcome. Error bars represent standard errors of the mean. Effect sizes $\left(\eta^{2}\right)$ are as follows: (a) for the interaction between legal procedure and outcome: .04; and (b) for the effect of outcome in the adversarial system: .12.

** denotes $p<.001$. 


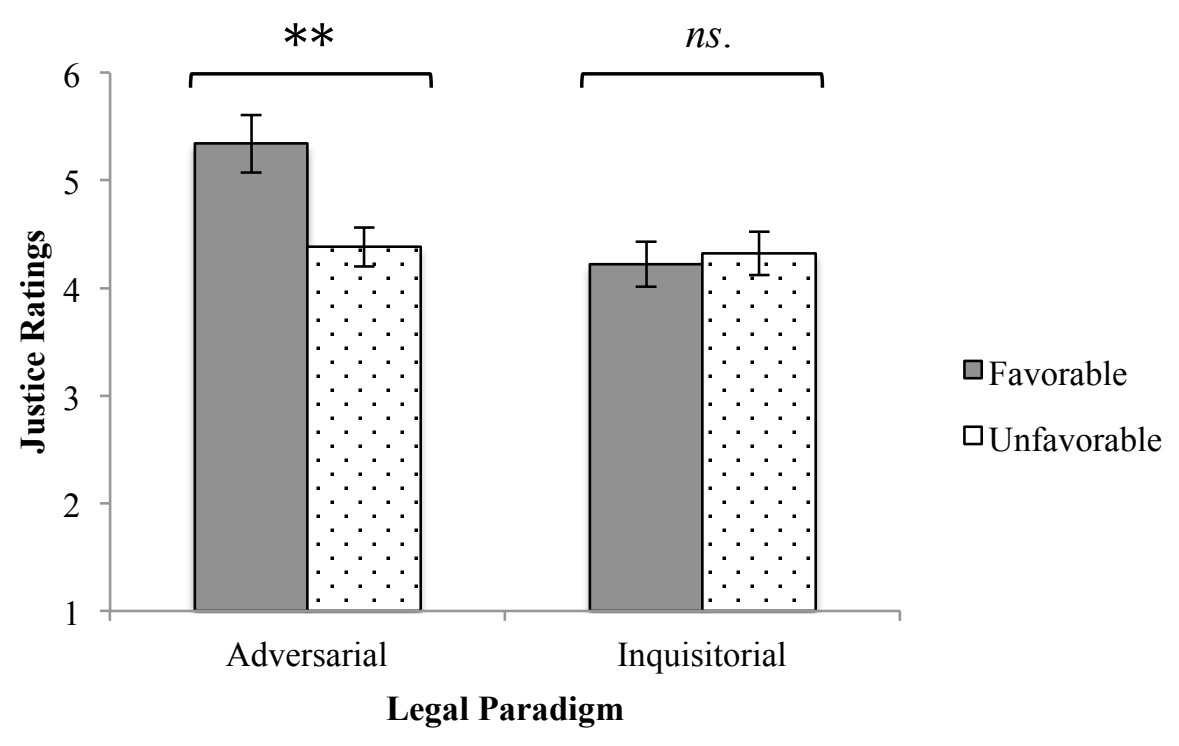

Figure 4. Perceptions of justice as a function of legal procedure and outcome. Error bars represent standard errors of the mean. Effect sizes $\left(\eta^{2}\right)$ are as follows: (a) for the interaction between legal procedure and outcome: .03; and (b) for the effect of outcome in the adversarial system: .13.

$* *$ denotes $p<.001$. 


\section{Footnotes}

1. Although it was not statistically significant, the analysis revealed a marginal effect of case type, such that evaluations of the truth and justice produced in criminal cases $(M=4.73, S D=1.05)$ were higher than evaluations of the truth and justice produced in civil cases $(M=4.31, S D=1.30)$.

2. Bonferroni analyses were conducted on all planned comparisons to reduce the likelihood of Type I error. All effects reported in Study 1 remained statistically significant under the conservative Bonferroni procedure (all $p \mathrm{~s}<.01$ ).

3. Because no three-way interaction existed between procedure, outcome, and evaluation, evaluations of truth and justice are plotted together in Figure 2 as a composite "evaluation" variable.

4. Bootstrapping is a nonparametric technique for testing indirect effects that does not assume that the variables of interest are normally distributed. The bootstrapping technique takes a large number of samples, with replacement, from the data and computes the indirect effect for each sample. The $95 \%$ confidence interval is derived by sorting the elements of the vector of the indirect effect from low to high. For a sample of 5000, the 250th score in the sorted distribution defines the lower limit of the confidence interval, and the upper limit is defined as the 4751 st score. If the confidence interval does not include a value of 0 , the indirect effect is statistically significant (see Preacher \& Hayes, 2004). 


\section{Appendix}

Below is a sample vignette used in the studies reported in this manuscript. All vignettes are available from the author by request and are available online at the American Psychological Association's website.

\section{Sample Vignette}

There are many ways in which decision makers can resolve legal disputes. For example, sometimes people have those disputes settled in a court of law. Other times, they have their cases resolved through a process called "arbitration," where a neutral third-party (who isn't always a judge) will decide the case instead of a jury, or through a non-binding process called "mediation." Helping policy makers study different methods of resolving legal disputes may aid the legal system in functioning more efficiently and more affordably. In studying different methods of solving legal disputes, policy makers often look to what members of the public think about these methods, because if there is widespread support, the methods might be implemented more quickly. Thus, we ask for your help today.

With this in mind, please carefully read the short vignette (hypothetical story) on the following page and think carefully about the way in which the legal dispute is resolved. (We'll ask you questions about what you've read.) Authorities currently disagree about the appropriateness of the methods used to resolve the dispute in the vignette, and so your feedback is very much appreciated.

In the vignette, we ask that you imagine that you are suing a drug manufacturer for an illness that you believe the drug caused. The vignette is relatively short, but we ask that you read the vignette (and answer the questions that follow) as if it were a real 
trial. At the trial, you and the drug manufacturer agree on all of the important facts except one: whether a popular antibiotic drug led to a severe stomach illness you contracted (which caused you to spend several weeks in the hospital and miss several weeks of work). This is the main issue to be resolved at the trial.

Here is the process the court will use to resolve the dispute:

- Each party (you, the "plaintiff," and the drug company, the "defendant") will present their own witnesses and their own case to the jury. The court will decide the case based on those presentations.

- Each party may also present their own expert scientific witness to testify about the effects of the drug.

- Each party pays for their own expert, should they decide to hire one, and may look at different experts until they find one who is acceptable to them and will testify on their behalf. Neither party has to tell the other one (or the court) the identity of the experts they looked at before they chose the one who ultimately testifies.

- The lawyers for both parties have the opportunity to ask questions of each other's witnesses.

You have called several witnesses, including your family members (who can attest that you took the medication) and your family doctor (who can attest to your symptoms at the hospital). The drug company's lawyer did not ask any questions of these witnesses. You also hired an expert witness to testify. In response to your lawyer's questions, your expert testifies as follows:

- He received his Ph.D. in biology from Harvard University. 
- Several studies conclusively show that the defendant's antibiotic causes stomach bleeding in rats and mice in the laboratory.

- Animal studies can tell us a lot about the effects of chemicals on humans.

- Almost every substance that has been shown to cause stomach bleeding in humans was first shown to be a cause of stomach bleeding in animals.

In response to questions from the drug company's lawyer, your expert testifies as follows:

- You are paying him $\$ 2000$ for his testimony, which he says is the customary rate.

- He has testified as an expert in over 50 cases involving defective drugs, but he claims that he is unbiased.

- Humans and rats are different species.

- A study of human beings revealed that, over the span of 5 years, only a few more people got sick after taking the drug than we would expect by mere chance.

- Human studies might require more time for the effects of the drug on humans to be apparent.

After all of the testimony was heard, both attorneys gave closing arguments to the court. The court was required to find in your favor if it believes by a preponderance of the evidence (i.e., that it is more likely than not) that the drug company's medication caused your illness. The court later returned a verdict in your favor. 